REVISTA X, Curitiba, volume 14, n.4,p. 256-276, 2019

\title{
FILHOS OUVINTES DE PAIS SURDOS: LINGUAGEM, IDENTIDADE(S) E ESCOLARIDADE
}

Hearing children of deaf parents: language, identity(ies) and schooling

\author{
Eliziane Manosso STREIECHEN - UNICENTRO ${ }^{1}$ \\ Gilmar de Carvalho CRUZ - UNICENTRO ${ }^{2}$ \\ Cibele KRAUSE-LEMKE - UNICENTRO ${ }^{3}$
}

\begin{abstract}
RESUMO: Desde a oficialização da Libras (BRASIL, 2002) e com o advento da inclusão dos alunos surdos nas salas de aula, a maioria dos estudos passou a focar o sujeito surdo, com ênfase na aquisição da linguagem, escolaridade entre outros aspectos biopsicossociais que permeiam essa população. No entanto, há segmentos envolvidos diretamente no contexto da surdez que quase não figuram nas pesquisas: os filhos ouvintes de pais surdos. Há muitos aspectos a serem desvendados sobre eles, visto que vivenciam situações cotidianas muito singulares. Neste artigo, abordam-se questões identitárias, linguísticas e escolares que, de alguma forma, trazem implicações para a vida desses sujeitos. Destaca-se que a maioria dos filhos ouvintes torna-se bilíngue e isso pode gerar certas dificuldades na aquisição da linguagem escrita. A maioria dos filhos torna-se 'intérpretes' de seus pais surdos. Alguns podem apresentar problemas emocionais, sociais, escolares e outros.
\end{abstract}

PALAVRAS-CHAVE: Filhos ouvintes de pais surdos; Identidade; Libras; Surdos; Coda.

ABSTRACT: Since the officialization of the Brazilian Sign Language - Libras (BRASIL, 2002) and with the advent of deaf students inclusion in the classrooms, most of the studies began to focus on the deaf subject, emphasizing language acquisition, schooling among other biopsychosocial aspects that permeate these citizens. However, there are segments directly involved in the context of deafness that hardly ever appear in the researches: hearing children of deaf parents. There are many aspects to be unveiled about them, since they experience very unique daily situations. In this article, we address identity, linguistic and schooling issues

\footnotetext{
${ }^{1}$ Doutora em Educação pelo Programa de Pós-Graduação em Educação da Universidade Estadual de Ponta Grossa/PR. Mestre em Educação pelo Programa de Pós-Graduação da Universidade Estadual do Centro-Oeste - Unicentro - Paraná - Paraná. Atualmente é Professora de Libras, lotada no Departamento de Letras da Unicentro/PR. E-mail: lizi_st@yahoo.com.br.

${ }^{2}$ Doutor em Educação Física pela Universidade Estadual de Campinas. Mestre em Educação pela Universidade do Estado do Rio de Janeiro (UERJ). Professor da Universidade Estadual do Centro-Oeste Unicentro/PR. Membro do Corpo Docente do Programa de Pós-Graduação em Educação da Universidade Estadual de Ponta Grossa (UEPG) e do Mestrado em Educação da Unicentro/PR. E-mail: gilmailcruz@gmail.com.

${ }^{3}$ Doutora em Educação pela Universidade de São Paulo. Mestre em Letras pela Universidade Católica de Pelotas. Professora da Universidade Estadual do Centro-Oeste - Unicentro - PR. Membro do Corpo Docente do Programa de Pós-Graduação em Letras - PPGL e Educação - PPGE Universidade Estadual do Centro-Oeste - Unicentro - PR. E-mail: cklemke@ gmail.com.
} 
REVISTA X, Curitiba, volume 14, n.4,p. 256-276, 2019

that, in some way, bring implications for the life of these subjects. It is emphasized that the majority of the hearing children becomes bilingual and this may generate certain difficulties in the acquisition of written language. Most children become 'interpreters' of their deaf parents. Some may present emotional, social, schooling, and other problems.

KEYWORDS: Hearing children of deaf parents; Identity; Libras; Coda.

\section{INTRODUÇÃO}

O objetivo deste artigo é destacar as principais discussões realizadas por alguns pesquisadores sobre as características dos filhos ouvintes de pais surdos, com vistas à formação de sua(s) identidade(s), linguagens, escolaridade, entre outros aspectos.

No Brasil, os estudos sobre os filhos ouvintes de pais surdos são bastante escassos, pois, desde 1960, com o reconhecimento da língua de sinais (LS) como Língua, muitas pesquisas, tanto no campo da sociolinguística quanto no âmbito da educação, foram direcionadas aos surdos, com ênfase à aquisição da linguagem escrita, à inclusão escolar, à forma como os surdos se comunicam etc. (STREIECHEN, 2014).

Nesse cenário de pesquisas, sobre os filhos de pais surdos, existem algumas terminologias ou siglas utilizadas pelos pesquisadores para se referirem a esses sujeitos. A sigla mais comum é CODA (Children of Deaf Adults - traduzida como: 'filhos de pais surdos' ou 'filhos de surdos adultos').

Antes de 1983, os ouvintes, filhos de surdos, eram nomeados pela sigla inglesa HCDP (Hearing Children with Deaf Parentes - Crianças ouvintes com pais surdos). Nesse ano, 1983, com o surgimento da Organização Internacional 'CODA', cuja finalidade era dar assistência às crianças que tinham pais surdos, muitos desses filhos passaram a se identificar ou se autorreferenciar pelo nome dessa organização, ou seja, CODA (ANDRADE, 2011; QUADROS, 2017). Um CODA ${ }^{4}$, portanto, pode tanto ser surdo ou ouvinte, "uma vez que o que os faz ser CODA é o fato de ter pais surdos, ou ter sido educado por pessoas surdas" (SOUSA, 2012, p. 403).

Há também o termo KODA (Kids of deaf adults - Crianças de surdos), criado no final do século XX, nos Estados Unidos da América (EUA), por um grupo de surdos, com a finalidade de apoiarem-se mutuamente e promoverem atividades coletivas para

\footnotetext{
${ }^{4}$ Nesse trabalho, optamos por utilizar 'filhos ouvintes de pais surdos', por entendermos que o termo CODA ou KODA se refere a uma organização, assim, há de nossa parte um estranhamento ao utilizarmos essa sigla para nos referirmos a uma pessoa.
} 
seus filhos. Entretanto, diferentemente da instituição CODA, essa era restrita apenas aos surdos que tinham filhos ouvintes (ANDRADE, 2011).

Apesar de a articulação, nos EUA, entre as pessoas que têm pais surdos, ter se iniciado já há algum tempo - em 1983 - no Brasil, o I encontro dos filhos e filhas de pais surdos, com o tema 'Fiar e Desfiar', ocorreu na cidade do Rio de Janeiro/RJ, somente em 2013; em 2014, o II encontro, com o tema 'Lembranças', foi realizado em Belo Horizonte/MG; em 2015, o III encontro, com o tema 'Vi a mão', ocorreu em Porto Alegre/RS; em 2016, o IV encontro, 'Cuidando um do outro', foi no Rio de Janeiro/RJ, em 2017, o V encontro 'Experiências Codas' realizou-se também no Rio de Janeiro/RJ; em 2018, novamente no Rio de Janeiro/RJ, aconteceu o VI encontro, cujo tema foi 'Imaginário Coda' ${ }^{5}$. Atualmente, a equipe organizadora já está divulgando o VII encontro, 'Reconstruindo e construindo pontes com o universo surdo', que deverá ocorrer na cidade de Florianópolis/Santa Catarina, no mês de outubro de 2019.

A respeito dos encontros realizados no Brasil, Quadros (2017, p 65) declara que:

Esse encontro é esperado por cada um dos Codas, pois é a oportunidade de voltarem para o ninho e contarem com pessoas que compartilham a língua e acultura dos surdos brasileiros e, em especial, compartilham a experiência de ser coda. [...] as experiências vivenciadas e compartilhadas de cada encontro constituem momentos únicos de interação que se estabelecem a partir do que é partilhado, do que é comum, do que é igual. Esse igual, apesar de ser diferente para cada um, é o que garante a relação de identidade entre os codas (QUADROS, 2017, p. 65-66).

Bull (2013) - filho de pais surdos - ao participar ativamente desses encontros e perceber seu grau de importância para a sua vida e de seus colegas, filhos de pais surdos, destaca que:

Nós estamos, todos nós, em uma jornada em busca de cura e plenitude. Para os codas, o conflito cultural e as lutas de identidade podem ser resolvidos. Eu posso apontar para qualquer número de histórias pessoais de codas que, independentemente da idade, gênero ou nacionalidade, vivenciaram um avanço altamente significativo e pessoal quando eles "se encontraram" novamente no CODA. A experiência de "voltar para casa" e "meu povo" são ecos de experiências que as pessoas têm quando elas finalmente encontram uma comunidade no Mundo Surdo. Para filhos/as de pais surdos que não se sentem totalmente conectados ao mundo ouvinte, que não se sentem totalmente parte do Mundo Surdo, há um terceiro lugar onde

\footnotetext{
${ }^{5}$ Fonte: http://codabrasil.blogspot.com/2018/05/vi-encontro-nacional-de-codas.html.
} 
REVISTA X, Curitiba, volume 14, n.4,p. 256-276, 2019

elas podem estar $100 \%$ conectadas, integradas e em casa: no CODA e com outros codas. (BULL, 2013, p. 8)6.

Depoimentos como este, relatado por Bull (2013), nos levam a refletir e a valorizar esses encontros entre ouvintes que têm pais surdos, uma vez que isso lhes dá a oportunidade de conviver com o outro que é igual em sua diferença.

A partir de um levantamento no Banco de Teses e Dissertações da Coordenação de Aperfeiçoamento de Pessoal de Nível Superior (CAPES); no Instituto Brasileiro de Informação em Ciências e Tecnologia $\left(\right.$ IBICT) ${ }^{7}$, no Sistema de Información Cientifica Redalyc $^{8}$; bem como em alguns periódicos conceituados, dos últimos dez anos (20072017), encontramos vinte pesquisas, sendo doze nacionais e oito internacionais, sobre as pessoas ouvintes filhas de pais surdos. Esse número revela a incipiência em pesquisas nessa área, principalmente, quando os dados mostram que, no Brasil, há cerca de 5,7 milhões de pessoas surdas ou com algum tipo de deficiência auditiva ${ }^{9}$ (BRASIL, 2014). E, ao considerarmos que os surdos têm conquistado cada vez mais o seu espaço na sociedade - conseguindo usufruir direitos tais como: estudar com a mediação de intérpretes de Língua Brasileira de Sinais (Libras); ter empregos fixos; entender os programas televisivos; votar nas eleições; ter acesso aos programas de diversões (shows, esportes, teatro, viagens etc.) - precisamos ter em mente que muitos deles têm constituído famílias, aumentando, consequentemente, o número de ouvintes, cujos pais são surdos.

Algumas pesquisas, como a de Lane (1992), Wrigley (1996) e Quadros (1997), apontam que a maioria dos surdos, mesmo casados entre surdos, possui uma chance de 90 a $95 \%$ de gerarem filhos ouvintes. Bull (2013) aponta que nos Estados Unidos as estatísticas indicam que aproximadamente $90 \%$ das crianças surdas são nascidas em

\footnotetext{
${ }^{6}$ Todas as traduções são nossas.

7

Fonte: http://bdtd.ibict.br/vufind/Search/Results?lookfor=coda\&type=AllFields\&page=5http://www.redalyc.org/ home.oa

${ }^{8}$ Sistema de Información Científica Redalic Red de Revistas Científicas de América Latina y el Caribe, España y Portugal Universidade Autonoma del Estado de México Versión 2.2 beta, 2015: redalyc@redalic.org.

${ }^{9}$ Para a comunidade surda brasileira, existe uma diferença entre os termos 'deficiente auditivo' e 'surdo'. O primeiro "apresenta uma perspectiva técnica, clínica, médica, terapêutica. Não é errado usar a expressão. Os médicos não dizem 'você é surdo', eles dizem 'você é deficiente auditivo profundo', este é um termo técnico. Surdez é, também, uma expressão técnica. Surdo: apresenta uma perspectiva socioantropológica, uma definição social. Os surdos se identificam como surdos" (QUADROS, 2018). Fonte: http://cotidiano.sites.ufsc.br/educacao-para-surdos-no-brasil/. Acesso em 23 mar. 2018.
} 
famílias em que os pais são ouvintes. Esses dados desconstroem a crença de que todos os surdos podem gerar, exclusivamente, filhos surdos, exceto os casos de hereditariedade.

Grande parte dos estudos, sobre os filhos ouvintes de pais surdos, foca a identidade, a cultura e/ou as questões linguísticas dos filhos ouvintes de pais surdos. Essas pesquisas se justificam pelo fato de que esses sujeitos, em sua maioria, são considerados bilíngues, uma vez que eles adquirem, natural e simultaneamente, as duas línguas envolvidas em seus contextos familiares: a língua oficial do país - falada pelas pessoas com as quais eles convivem (parentes, vizinhos, amigos, professores etc.), mais a LS - utilizada pelos pais surdos.

\section{OUVINTES FILHOS DE SURDOS: IDENTIDADES DE FRONTEIRA 'ENTRE' CULTURAS DIFERENTES}

Primeiramente, nesse tópico, discorremos sobre a identidade, destacando também as diversas responsabilidades que alguns ouvintes assumem quando seus pais são surdos e, em seguida, elencamos os achados dos autores sobre as questões de linguagens e, finalmente, incluiremos as discussões sobre a escolaridade dos filhos de pais surdos.

Hadjikakou et al. (2009) realizaram uma pesquisa com dez ouvintes adultos, entre 21 e 30 anos de idade, de ambos os sexos, filhos de pais surdos. Moroe (2013) também desenvolveu um estudo com dez participantes, com idades entre 21 e 40 anos. Em ambas as pesquisas, os participantes tinham diferentes profissões e graus de escolaridade e o objetivo dos pesquisadores foi o de investigar as experiências vivenciadas na família, na escola e na sociedade pelas pessoas ouvintes que tinham pais surdos. Tanto o estudo de Hadjikakou et al. (2009) quanto de Moroe (2013) revelaram que os filhos ouvintes de pais surdos desenvolveram uma identidade bicultural pelo fato de conviverem entre dois 'mundos' diferentes, o 'mundo surdo' e o 'mundo ouvinte'.

Entretanto, o fato de um filho de surdo precisar se comportar, ora como se fosse surdo, ora como fosse ouvinte, "não significa dizer que pensamos estes filhos como se fossem metade surdo e metade ouvinte, mas que os vemos dentro de dois sistemas de referência, o de afirmação da diferença e o de mediador" (ANDRADE, 2011, p.115116). Esse autor explica também que os filhos de surdos "são representantes da ideia de identidade de fronteira que estamos desenvolvendo como especificidade identitária 
REVISTA X, Curitiba, volume 14, n.4,p. 256-276, 2019

legítima de pessoas, cujas experiências cotidianas estão marcadas pelo ser "entre"” (ANDRADE, 2011, p. 116).

Sousa (2012), ao investigar o percurso de vida de um grupo de dez filhos ouvintes de pais surdos - sendo cinco portugueses e cinco catalães - enfatiza que "este grupo pertence a uma maioria ouvinte, mas também pertence a uma minoria surda, constituindo por si só uma minoria dentro de uma outra" (SOUSA, 2012, 402). Essa autora não estende seus estudos na compreensão da construção da identidade. Ela se debruça sobre as questões do bilinguismo e do biculturalismo, pois, para ela, "esta questão das línguas é extremamente relevante, pois a língua gestual e a língua oral estiveram sempre presentes no crescimento linguístico e cultural de uma criança ouvinte filha de pais surdos, o que acaba por moldar a identidade CODA" (SOUSA, 2012, p. 403).

Gonçalves (2012) explica que os filhos ouvintes de pais surdos crescem em um ambiente bilíngue (língua oral e língua gestual) e bicultural (cultura nativa e cultura dos surdos), o que terá um impacto significativo no seu desenvolvimento, criando uma terceira identidade, situada no permeio da identidade surda e identidade ouvinte.

Souza (2014) - filho de pais surdos - ao buscar compreender como se estabelece o perfil profissional de oito tradutores/intérpretes de Libras, filhos de pais surdos, descobriu que $100 \%$ dos seus participantes se auto definem como surdo/ouvinte, e não como surdos ou ouvintes apenas, ou seja, "o filho de surdos não se considera totalmente 'ouvinte', ao mesmo tempo em que não se vê totalmente como surdo" (SOUZA, 2014, p. 109-110).

Quadros (2017), que colheu a história de seis filhos(as) de pais surdos brasileiros(as), incluindo a sua própria história, como filha de pais surdos, cita diversos elementos que unem os filhos de pais surdos, demonstrando o apreço que os entrevistados têm pela LS, uma vez que essa língua constitui e desempenha papel fundamental na construção da identidade desses sujeitos. Vejamos a seguir o depoimento da própria autora:

Depois de realizar essas conversas, percebi o quanto existe uma identidade comum entre todos os filhos de pais surdos, incluindo a mim, filha de pais surdos. Apesar de cada história ser única, temos muito em comum. O fato de crescermos em uma família que usa a língua de sinais e que não ouve a língua portuguesa nos une. As experiências com uma língua que é visuocorporal, paralelamente com uma língua fonocêntrica (oral-auditiva e escrita), nos conectam. A relação com uma comunidade surda, que é diferente da comunidade 
ouvinte à qual nós também pertencemos, nos une. Os olhares estigmatizados por parte dos outros (os ouvintes), com os quais nos deparamos ao longo da vida, nos unem. A mútua compreensão das histórias e dos sentimentos envolvidos, mesmo sendo únicos, nos une. $\mathrm{O}$ fato de nos darmos conta de que é importante voltarmos para nossa língua, não porque seja melhor, mas simplesmente porque é nossa língua, nos une. (QUADROS, 2017, p. 144).

Sobre a formação da identidade dos filhos de pais surdos, Skliar e Quadros (2000, p. 23-24) explicam que:

As identidades dessas crianças desenvolvem-se em meio a surdos adultos e, também, a ouvintes adultos. Aí reflete-se a contradição na formação da identidade desses 'ouvintes', ao mesmo tempo em que essas crianças desenvolvem experiências essencialmente visuais, e desenvolvem experiências auditivas. E o fato delas terem acesso às experiências auditivas enquanto ouvintes, tornam-nas diferentes dos surdos colocando-as a parte da comunidade de forma sutil [...]. Por outro lado, temos um tipo de 'ouvinte' que diferencia-se dos outros 'ouvintes', pois apesar dos filhos de pais surdos serem ouvintes, eles têm a experiência visual adquirida juntamente à comunidade surda $\mathrm{e}$ seus familiares.

Desse modo, o ouvinte filho de surdos incorpora certos padrões sociais na formação da identidade e o que não está de acordo com este padrão torna-se estranho e distingue-se do outro, conforme afirma Woodward (apud HALL, 2006): “[...] nossa identidade ao mesmo tempo em que é nossa, é dos outros". A definição que os outros fazem do 'eu' tem muito mais efeito do que a forma como esse 'eu' se autodefine. E o fato de um indivíduo se diferenciar em um grau maior daquilo que é aceitável dentro de uma comunidade ou de um grupo, pode afetar drasticamente aquele que é apontado como o diferente.

No entanto, é na perspectiva da desigualdade e não da diferença que tanto surdos quanto seus filhos ouvintes são visualizados pela sociedade. Os surdos são percebidos apenas como uma 'orelha' que não funciona, e não como pessoas dotadas de habilidades, desejos e sonhos, assim como qualquer outra pessoa. E os ouvintes, filhos de pais surdos, por sua vez, ao passarem pelo estigma de ter pais 'deficientes', também são considerados como desiguais, pois fogem ao padrão de pertencerem a uma família 'normal', em que todos são ouvintes, conforme mencionado por Gurjão (2013, p. 39): "Os filhos recebem uma identidade social que contem elementos que fazem parte da representação sobre os pais. Neste sentido, existe não apenas um compartilhamento de valores sociais e morais, mas do significado de "não-normal' que os surdos receberam". 
REVISTA X, Curitiba, volume 14, n.4,p. 256-276, 2019

O maior desafio dos surdos, e também de seus filhos ouvintes, é que essa perspectiva não é somente das pessoas distantes, daquelas com quem eles não têm contato, mas concentra-se, principalmente, dentro de suas próprias famílias que, ao acreditarem na sua incapacidade, tentam impedi-los de educarem e conviverem com seus filhos no dia a dia.

Em relação às responsabilidades que os filhos ouvintes assumem em seus lares, pelo fato de os pais serem surdos, Quadros e Masutti (2007), Andrade (2011), Pereira (2013), Streiechen, Cruz e Krause-Lemke (2015) afirmam que, muitas vezes, esses filhos precisam assumir certas responsabilidades desde crianças.

Sobre essa questão, Streiechen, Krause-Lemke e Cruz (2015) explicam que é preciso levar em conta que o fluxo de informações de uma família, em que todos são ouvintes, é muito maior do que naquela em que há surdos, especialmente quando esses surdos são os provedores da família, os pais. E, na maioria das vezes, o único canal de informação e interação com o mundo sonoro que os pais surdos têm, são os filhos ouvintes. E se os filhos não tiverem disposição para repassar tudo o que ouvem na vida social ou na mídia, os pais podem ficar à mercê de uma ignorância funcional. E, se os pais surdos ficam doentes, são seus filhos ouvintes que chamam alguma pessoa adulta para levá-los ao hospital; acompanham-nos ao supermercado, aos consultórios médicos, ao banco, à farmácia etc., conforme Silva (2016, p. 34) "interpretava/interpreto para meus pais, em diversas situações do cotidiano: assistindo novela, durante conversas em família, em consultas médicas, na escola, e também em situações mais formais como no trabalho, em negociações bancárias e até mesmo em formaturas".

Pereira (2013) revela que, para desbloquear um cartão de crédito, precisou fingir ser o próprio pai, visto que o desbloqueio só poderia ser realizado pelo titular da conta bancária, e via telefone. E o pai sendo surdo, não poderia falar ao telefone. O maior receio dos parentes ouvintes era de que a surdez dos pais pudesse prejudicar o desenvolvimento da fala e da alfabetização de Pereira. Entretanto, ele afirma que a convivência com seus pais surdos, bem como, a aprendizagem da LS, resultaram em uma profissão como professor/intérprete de Libras, a qual ele exerce com muita satisfação.

Silva (2016, p. 117) relata que sua função de mediar a comunicação entre surdos e ouvintes ocorria, além da escola, do trabalho, entre outros espaços, nas associações de surdos "vivendo em um mundo, por vezes, silencioso, outras vezes, silenciado, que, junto às associações [...], onde a cultura surda se constitui, já que é nesses momentos 
REVISTA X, Curitiba, volume 14, n.4,p. 256-276, 2019

que acontecem as interações, as trocas de informações, reuniões para organização de seus movimentos e lutas" (SILVA, 2016, p. 117).

O exercício de interpretar para os pais está entre o aspecto de maior negatividade denunciada pelos participantes desses pesquisadores, ocasionando amadurecimento rápido e perda de parte da infância. Destacamos, a seguir, dois depoimentos dos participantes de Sousa (2012) e de Streiechen, Cruz e Krause-Lemke (2015) que ilustram essa realidade: "Eu era apenas uma criança e não se passa a infância como qualquer outra criança, a minha infância foi a pensar nos meus pais, a protegê-los a ajudá-los, têm que ir ao médico, têm que falar na escola e quem traduzia era eu". (Inês). (SOUSA, 2012, p. 408). “[...] havia muita exigência da sociedade. Por eu ser ouvinte tinha que entender meus pais como se eu fosse responsável por eles. Meus pais eram muito dependentes de mim” (R) (STREIECHEN; CRUZ; KRAUSE-LEMKE, 2015, p. $41)$.

Pereira (2013) declara que, desde os cinco anos de idade, interpretava telejornais, filmes entre outros programas televisivos que interessassem aos pais. "O que ele falou?" Era a pergunta frequente dos pais a Pereira. Porém, diferentemente de outros ouvintes, que concebem o exercício da interpretação como um fardo que lhes tira a oportunidade de usufruir de suas infâncias, Pereira (2013) afirma que gostava disso, pois, se sentia importante e, atualmente, continua interpretando para a esposa que também é surda. Como ponto negativo dessa ação, ele desabafa que: "nas reuniões de pais realizadas pela escola, eu ficava com as mães, pais e professores ouvindo os relatórios de cada um de nós, enquanto meus colegas estavam brincando na quadra”. Sua visão sobre essas tarefas é a de que:

Os filhos de pais surdos, ao se depararem com um mundo não acessível para a pessoa surda, acabam tendo que acompanhar os pais em locais em que uma criança não teria a necessidade de ir, além de ter acesso à informações que não lhes são 'convenientes' [...]. Saber o saldo bancário do pai ou da mãe, ligar para um parente para avisá-lo sobre um problema grave de saúde ou assistir a uma reunião de pais e professores não deveriam, necessariamente, ter a participação de uma criança. Entretanto, no caso dos CODA, isso é comum, o que lhes dá (entre os quais eu me incluo), uma responsabilidade precoce. (PEREIRA, 2013, p. 61).

Dos oito participantes do estudo de Souza (2014), sete afirmaram que precisaram interpretar para os pais com grande frequência, além de atuarem como intérpretes para amigos surdos dos pais, porém desprovidos de técnicas específicas de 
interpretação, assim sendo executavam a ação por serem filhos de pais surdos e não por serem intérpretes de LS. Muitos desses filhos, quando adultos, acabam optando por fazer da tradução e interpretação uma profissão. Dos dez participantes da pesquisa de Moroe (2013), sete tornaram-se tradutores/intérpretes de LS profissionais. O estudo de Quadros (2017), da mesma forma, demonstra que todos os seis entrevistados (cinco pessoas do sexo feminino, incluindo a autora, e uma do sexo masculino) em algum momento, precisaram mediar a comunicação entre seus pais e os ouvintes. Alguns de seus participantes avaliaram essa tarefa como difícil e outros como honrosa, segundo a autora.

Melo (2015) sugere que a presença de ouvintes filhos de surdos dentro dos ambientes escolares, muitas vezes, se confunde com o papel de tradutor e intérprete de LS, o que deve ser (re)pensado e (re)discutido com mais profundidade. É preciso considerar que só o fato de ser filho de surdos não garante recursos linguísticos apropriados e especificidades exigidas para exercer a função de intérprete de LS. Nem todos nós nos tornamos professores de Língua Portuguesa (LP) apenas pelo fato de nos comunicarmos por meio dela. Isso é válido para qualquer outra língua, oral ou sinalizada. Para se tornar intérprete de LS é preciso que todos, inclusive os filhos de surdos, passem por uma formação acadêmica que lhe dê garantias de fluência e conhecimentos sobre todos os aspectos específicos da LS e estratégias necessárias para essa profissão.

Nesse caso, de a criança ouvinte precisar assumir a posição de 'intérprete' para os pais surdos na escola e em outros lugares públicos, é notório que, normalmente, o que se constam nas leis nem sempre é sinônimo de ação. Se assim o fosse, todas as instituições púbicas brasileiras, desde o ano de 2004, a partir da obrigatoriedade do Decreto $n^{\circ} 5.296 / 2004$, já teriam extinguido qualquer tipo de barreira comunicativa entre surdos e ouvintes em todos os locais públicos. Entre os diversos serviços, dos quais as pessoas com deficiências têm direitos, esse Decreto, em seu Capítulo II, Art. $6^{\circ}$, $\S 1^{\circ}$, prevê "serviços de atendimento para pessoas com deficiência auditiva, prestado por intérpretes ou pessoas capacitadas em Língua Brasileira de Sinais - LIBRAS e no trato com aquelas que não se comuniquem em LIBRAS [...]” (BRASIL, 2004).

Um dos principais entraves que as políticas públicas de inclusão têm se deparado, na área da surdez, concentra-se especialmente na escassez do profissional tradutor e intérprete de língua de sinais (TILS) para sanar todas as necessidades de demanda. 
REVISTA X, Curitiba, volume 14, n.4,p. 256-276, 2019

A seguir, trazemos os principais apontamentos sobre as questões linguísticas que demarcam uma fronteira entre a comunicação surda e a comunicação ouvinte desses sujeitos.

\section{A ZONA DE FRONTEIRA ENTRE A LÍNGUA DE SINAIS E A LÍNGUA ORAL: A QUAL MUNDO LINGUÍSTICO PERTENCEM OS FILHOS DE SURDOS?}

No que diz respeito às diferentes formas com que os filhos ouvintes precisam se comunicar com seus pais surdos, transitando de uma língua a outra, durante quase todo o tempo em que estão presentes no mesmo lugar dos pais, Quadros e Masutti (2007, p. 263) descobriram que: "o CODA se constitui com ambas estruturas linguísticas que se mesclam e interagem na constituição de sua subjetividade, especialmente quando a experiência com o bilinguismo se dá sem a violência colonial e o recalque da língua de sinais".

Kanto, Laakso e Huttunen (2015), que estudaram as diferenças pragmáticas no uso de gestos com a estutura de sinais produzidos por oito crianças ouvintes, filhas de pais surdos, entre as idades de doze, dezoito e vinte e quatro meses, descobriram que essas crianças, ainda muito precoces, já são capazes de usar tanto a LS quanto a língua oral, de forma diferenciada no que tange aos seus interlocutores.

Os achados da pesquisa de Bishop e Hicks (2008, p. 3), que abordaram as escolhas linguísticas de três crianças surdas com suas mães surdas, vão ao encontro dessa afirmação: “crianças ouvintes que crescem em famílias surdas aprenderão a língua de sinais bem como a língua oral. Uma condição necessária é que Kodas sejam expostas a ambas as línguas" (BISHOP; HICKS, 2008, p. 3). E essa aprendizagem ocorre de forma natural, conforme revela um dos participantes de Hadjikakou et al. (2009, p. 492): "Eu cresci em um ambiente em que você não pode fazer de outra forma, senão sinalizar. Eu e meu irmão aprendemos a falar com as mãos. Eu via meus pais sinalizando e pensava que era normal (P1)".

No entanto, segundo Bishop e Hicks (2008), as crianças ouvintes de pais surdos aprendem muito mais a LS quando os pais estão envolvidos com a comunidade surda do que aquelas em que a LS é utilizada apenas em casa. Portanto, "o ambiente familiar linguístico não é decisivo ao explicar a variação da escolha linguística" (BISHOP; HICKS, 2008, p. 18) de algumas crianças ouvintes filhas de pais surdos. Isso porque há que se levar em conta que, muitas vezes, os pais, mesmo sendo surdos, optam pela comunicação via oralidade, por receio de que seus filhos não se desenvolvam nessa 
REVISTA X, Curitiba, volume 14, n.4,p. 256-276, 2019

modalidade linguística e sejam afetados futuramente (KANTO, LAAKSO, HUTTUNEN, 2015; QUADROS, 2017).

Sousa (2012, p. 411), ao se debruçar sobre as questões do bilinguismo e do biculturalismo dos filhos ouvintes de pais surdos, postula que esses "detém duas línguas maternas - uma maioritária e outra minoritária, uma oral e outra gestual, uma pertencente a indivíduos que a sociedade rotula como 'normais' e a outra aos que rotula de 'deficientes"'.

Um dos pontos levantados por Quadros (2017, p. 66), é que os filhos ouvintes de pais surdos, mesmo sendo brasileiros, acabam enfrentando desafios semelhantes aos imigrantes, pois, "precisam aprender uma cultua estranha do lado de fora de sua família”, ou seja, aprender a cultura do ouvinte que difere da cultura dos pais surdos. Segundo a autora, "cabe aos filhos de pais surdos darem um jeito de aprenderem a lidar com essas culturas, com as duas línguas e com as atitudes e os valores dos surdos e dos ouvintes”. (QUADROS, 2017, p. 66).

Há relatos, nas pesquisas de Pereira (2013), Streiechen, Cruz, Krause-Lemke (2015); Souza (2014), que denunciam os conflitos desencadeados pela comunicação peculiar de alguns alunos filhos de pais surdos dentro das escolas. Vejamos o depoimento de uma das participantes do estudo de Pereira (2013, p. 70), no qual ela relata um episódio ocorrido em sala de aula, onde a professora tenta corrigir sua fala: “Hermione, o correto é: 'eu vou para casa' e não 'casa vou'. Eu falava muito errado. Eu falava 'corariam' por quê? A voz dos meus pais saia dessa forma teve que fazer fono para poder falar melhor" (Hermione) (PEREIRA, 2013, p. 96).

Nessa mesma direção, Souza (2014) afirma que seus participantes encontraram muito mais dificuldades para aprender a LP, em sua modalidade oral e escrita, do que a LS, demonstrando, inclusive, frustração em se comunicar por meio da LP falada e escrita em diversas situações de sala de aula, em ambiente de trabalho ou com amigos. Para os participantes do estudo de Souza (2014), a LS, ou seja, a sinalização continuava sendo a melhor opção de expressão, mesmo na fase adulta.

Ao estudarem a alternância de línguas de crianças ouvintes filhas de pais surdos, Sousa e Quadros (2012) afirmam que essa alternância poderá influenciar a aprendizagem da língua oral na modalidade escrita, uma vez que "estruturas e itens lexicais de uma língua podem ser transferidos para a outra em situações de bilinguismo - trazendo, portanto, implicações para sua escolarização" (SOUSA; QUADROS, 2012, p. 331). 
REVISTA X, Curitiba, volume 14, n.4,p. 256-276, 2019

Quadros (2017) explica que a dificuldade com a LP escrita irá depender, basicamente, das experiências que cada filho de pais surdos tem com a língua de sinais. Segundo a autora, normalmente, "essa dificuldade acontece nos primeiros anos escolares [...]. Provavelmente, as experiências de entrada no mundo ouvinte interferem na relação com a língua portuguesa, de forma mais ou menos marcante" (QUADROS, 2017, p. 221).

Essa dificuldade de lidar com as línguas pode interferir ou dificultar a comunicação do filho ouvinte de pais surdos, podendo criar bloqueios na comunicação entre ele e a comunidade escolar. Por estarem inseridos nesse meio cultural, diferente daquele no qual estão as crianças que têm pais ouvintes, os filhos de surdos, nessa relação natural e cotidiana com o pai, a mãe ou ambos surdos, podem desenvolver vários traços identitários, apoderando-se dos elementos linguísticos e culturais praticados no contexto em que vivem. Eles precisam procurar formas para agir e reagir diante das inúmeras situações em que se encontram diariamente. Por exemplo, se um filho de surdos está apenas na presença dos pais, sua atitude será muito diferente de quando ele está apenas entre ouvintes. Ele usa línguas distintas para cada contexto e também precisa sempre explicar para as pessoas ouvintes, as quais não estão dentro da cultura surda, o que seus pais estão expressando em LS e vice-versa. Ele faz a ponte, a mediação entre os dois mundos: surdo e ouvinte.

Quadros (2017, p. 70), fundamentada em Hoftmeister (1998), usa a metáfora do 'efeito camaleão' para significar o comportamento dos filhos de surdos, os quais precisam se adaptar de acordo com a cultura que vivenciam em determinados momentos, ou seja, "quando está entre ouvintes, passa a ser como os ouvintes, e quando está com os surdos, passa a ser como os surdos".

A partir das questões descritas e discutidas nos trabalhos dos autores acima citados, podemos considerar que viver na zona fronteiriça, entre o mundo surdo e o mundo ouvinte, pode influenciar no processo de formação da(s) identidade(s) e subjetividade das crianças que têm pais surdos e, consequentemente, em seu desenvolvimento escolar. Com isso, podemos compreender que a surdez dos pais não significa apenas o fato de eles não ouvirem e não usarem a voz para falar. A surdez dos pais perpassa a perda sensorial ou a falta de comunicação por meio da oralidade. Essa surdez acarreta estranhamento por boa parte da sociedade e deriva certo estigma, que faz com que tanto pais quanto filhos precisem constantemente equacionar os diversos 
REVISTA X, Curitiba, volume 14, n.4,p. 256-276, 2019

problemas e necessidades que encontram diariamente não somente pela surdez, mas, sobretudo pela falta de conhecimento e empatia do outro em relação a esses desafios.

Depois dessa breve explanação sobre os entraves identitários e linguísticos que os filhos ouvintes de pais surdos se deparam no decorrer de suas vidas, veremos, a seguir, os obstáculos que eles encontraram também no seu percurso escolar.

\section{O QUE DIZEM AS PESQUISAS SOBRE A ESCOLARIZAÇÃO DOS FILHOS OUVINTES DE PAIS SURDOS?}

As discussões, em torno da escolaridade dos filhos de pais surdos, são abordadas sutilmente pelos autores e apenas quando há depoimentos dos participantes, relatando os conflitos e desafios pelos quais passaram na vida escolar, sem, contudo, aprofundarse nessa questão.

Quadros (2017, p. 221), por exemplo, a partir dos relatos de seus participantes e de sua própria experiência, destaca que "a escola é um acontecimento na vida desses codas, que apresenta um impacto significativo nas relações estabelecidas pelas zonas de contato. Inicialmente, a escola representa um espaço de desconforto para a maioria dos entrevistados".

Entre os principais conflitos escolares vivenciados pelos filhos ouvintes de pais surdos, os pesquisadores destacam a dificuldade de aprender a língua oral e a escrita, uma vez que estão habituados a falar sempre por meio da LS, principalmente quando há mais surdos na família (avós, tios, primos...) além dos pais. Vejamos um relato de uma das participantes de Pereira (2013):

Eu tive muitas dificuldades em aprender o português até hoje eu tenho. Principalmente na hora de escrever. Quando eu comecei na escola eu lembro que... eu achava tudo muito novo. Nossa! Vou falar com a boca! Não vou falar com as mãos! [...] pra mim era 'casa vou' [...] então foi e ainda é muito difícil de passar para o papel o que você está pensando em Libras. (Hermiose). (PEREIRA, 2013, p. 97).

Para explicar os motivos pelos quais os filhos ouvintes de pais surdos se deparam com desafios para lidar com as duas línguas (LS + LP) no processo de escolarização, Streiechen (2018) traz o seguinte exemplo da ordem sintática da LP e da LS: "Eu gosto de sol" (Português). Essa mesma frase, sinalizada em LS ficaria assim: “SOL EU GOSTAR" (Libras).

A partir desse exemplo, podemos perceber que a ordem do sujeito, do verbo e do objeto não é sinalizada, em LS, na mesma ordem em que se fala em LP. Na frase em 
LS, o objeto SOL é o primeiro elemento a ser mencionado. Observamos, também, que a conjunção 'e', presente na frase em LP, não foi sinalizada, pois, "enquanto que no português há elementos conectivos indicados com palavras, na Libras, esses mecanismos são discursivos e espaciais, estando incorporados ao movimento ou em referentes espaciais" (FERNANDES, 2012, p. 62). Assim, os conectivos (conjunções, preposições, artigos e alguns tipos de verbos) não são sinalizados. Podemos perceber ainda que o verbo GOSTAR permanece no infinitivo, ou seja, não sofre flexão mesmo estando na $1^{\mathrm{a}}$ pessoa do singular.

Apesar de as crianças ouvintes de pais surdos estarem imersas no mundo ouvinte e em contato permanente com a LP desde bebês (avós, tios, primos, vizinhos etc.), as pessoas com quem elas mais interagem, em casa, normalmente, são os pais. Isso tem um peso relevante ao considerarmos que o modo como os surdos se comunicam, por meio da LS, difere consideravelmente do modo como nós ouvintes nos comunicamos, por meio da LP. Dessa forma, os filhos dos surdos acabam internalizando, natural e simultaneamente, as duas estruturas linguísticas (LS+LP). Às vezes, dependendo do contexto familiar em que a criança está exposta, é possível que a cultura linguística da LS se sobreponha à LP. O que ocorre é que, na escola, essa criança, que está muito mais habituada com a LS, precisa utilizar as regras apenas da LP e 'libertar-se' da estrutura da LS. Nesse panorama, Pereira (2013, p. 57-58) ressalta que: "ao escrever esse aluno pode trazer elementos da ordem de construção da língua de sinais, levando a professora, que desconhece essa língua, a acreditar que ele está apresentando dificuldades de aprendizagem".

Alguns dos participantes do estudo de Andrade (2011) revelam que sentiam algum tipo de constrangimento pelo fato de os pais serem surdos, principalmente quando precisavam se comunicar publicamente com os pais. Vejamos alguns desses depoimentos: "A vergonha que eu tinha é que a gente andava de ônibus e eu gostava demais de conversar. Até hoje a gente 'bate altos papos'. E, aí, a gente ia conversar no ponto do ônibus e o povo ficava olhando" (Amanda). "Tive alguns momentos de vergonha com meus amigos. Os pais deles eram ouvintes, tinham mais facilidade, as pessoas aceitavam mais". (Beatriz). "Eu ficava com vergonha. Ficava assim: 'Nossa o que eles vão pensar de mim?', que eu tenho alguma doença, que eu não posso ser saudável ou que eu carrego alguma coisa que contamina. É bem duro assim”. (Paula). (ANDRADE, 2011, p. 87-88). 
Esses depoimentos revelam que a LS, apesar de sua difusão no Brasil, não possui o mesmo status linguístico das demais línguas. Quando uma pessoa fala publicamente, por meio da LP e Inglesa ou francesa, por exemplo, logo, subentende-se que ela é bilíngue e dotada de certa inteligência, pois domina dois códigos linguísticos. Isso faz com que muitos demonstrem admiração por essa pessoa bilíngue. Entretanto, quando uma pessoa fala por meio da LP e da LS, subentende-se que uma delas é 'deficiente' e isso desperta preconceito ou piedade por parte de muitas pessoas, pois "o valor atribuído à surdez como falta exerce influência direta no uso da língua de sinais" (QUADROS, 2017, p. 68). Além disso, a LS "é a marca que evidencia a presença de uma pessoa surda" (PEREIRA, 2013, p. 48) e "a cultura dominante vê a surdez como algo ruim" (QUADROS, 2017, p. 68). O estigma ou o preconceito, portanto, estão associados tanto à LS - considerada a 'linguagem dos surdos-mudos'; 'linguagem dos gestos' - que a desvalorizam e a deixam em um patamar inferior às demais línguas de prestígio, quanto à pessoa surda - que se comunica por meio dessa língua - considerada 'deficiente' e, portanto, incapaz de exercer sua própria cidadania. De acordo com Quadros (2017, p. 25) "o ponto de vista da surdez como ausência de audição define as pessoas surdas como deficientes. Dessa forma, as línguas de sinais não são consideradas línguas, mas sim instrumentos para 'ajudar' essas pessoas a se tornarem melhores ('normais') ou serem curadas da surdez". A partir de suas experiências escolares e o modo como seus pais surdos eram vistos, Quadros (2017, p. 152) revela que “[...] a Libras não era considerada língua. Eles pareciam que 'olhavam' para meus pais como 'pobres coitados que eram surdos', não como gente normal'.

Hadjikakou et. al. (2009) também identificaram que um dos maiores desafios dos participantes do estudo estava relacionado ao olhar diferenciado da sociedade aos pais surdos. Esse estigma, que tantos surdos quanto os filhos de surdos vivenciam, por se comunicarem por meio de uma língua considerada minoritária e sem prestígio social, pode fazer com que alguns filhos ouvintes de pais surdos não se sintam confortáveis em conversar com seus pais surdos em público.

Além das entrevistas com os filhos de surdos, Pereira (2013) analisou alguns depoimentos dos pais surdos em relação aos filhos. No aspecto escolar, um desses pais dá o seguinte depoimento:

Ele começou a ir para a escola e começamos a perceber que na $1^{a}$ séria ele tinha muita dificuldade. Ele começou a ficar angustiado e preocupado. A professora também. Mas eu disse para ele, olhe filho, 
olhe para o seu pai. Lá na escola as pessoas são ouvintes. Você se acostumou com uma família surda, usuária da LIBRAS. Divida seu cérebro em dois. Uma parte é ouvinte e a outra usa LIBRAS. Quando você estiver com alguma dúvida, não fique esperando. No mundo ouvinte os pais podem ajudar, mas para nós surdos é mais difícil. (Pai de Colin). (PEREIRA, 2013, p. 97).

Diante desses depoimentos, entendemos que os ouvintes filhos de pais surdos enfrentam inúmeros desafios no seu dia a dia. Entretanto, no Brasil, não há leis e/ou discussões que contemplem a inclusão escolar de filhos ouvintes de pais surdos. Assim, a desinformação da maioria dos professores, sobre a cultura e questões linguísticas desses alunos, normalmente, é nutrida por rótulos que podem ocasionar marcas profundas na escolarização e na vida desses sujeitos.

Enfim, são tantas experiências diferentes vivenciadas pelos filhos ouvintes de pais surdos que, conforme Souza (2014, p. 111), não se pode ensinar em um curso, "mas tem a ver com a singularidade que apenas quem tem pais surdos pode entender". E a escola precisa estar atenta aos indícios de qualquer tipo de intolerância ou baixo rendimento escolar de alunos ouvintes, filhos de pessoas surdas, para que, dessa forma, possa tomar as iniciativas coerentes e de acordo com cada caso, a fim de ofertar igualdade de oportunidades e possibilidades para todos, conforme determinam as leis e diretrizes educacionais brasileiras que dizem respeito à inclusão.

\section{CONSIDERAÇÕES FINAIS}

Os filhos ouvintes de pais surdos vivenciam uma cultura familiar distinta daquela das crianças que têm pais ouvintes. Entre os principais resultados, destacamos os seguintes:

a) Alguns filhos de surdos tornam-se sujeitos bilíngues, pelo fato de se comunicarem por meio de duas línguas de sinais - utilizada pelos pais; e a língua oral utilizada pelos ouvintes que os rodeiam.

b) $\mathrm{O}$ exercício que os filhos assumem, de interpretar informações do mundo ouvinte aos pais surdos e vice versa, está entre os principais aspectos de negatividade, pois essa responsabilidade, muitas vezes, impede que esses sujeitos usufruam de sua infância e isso, muitas vezes, faz com que os papeis se invertam, ou seja, ao invés dos pais tomarem conta dos filhos, são os filhos que tomam conta dos pais. 
REVISTA X, Curitiba, volume 14, n.4,p. 256-276, 2019

c) Há filho de surdos que se sente constrangido ao se comunicar com os pais, por meio da LS, em ambientes públicos, diante dos olhares curiosos e, às vezes, preconceituosos da sociedade.

d) Alguns alunos ouvintes, filhos de pais surdos, encontram inúmeras dificuldades associadas ao processo de escolarização. Uma dessas dificuldades está atrelada à escrita, visto que eles se comunicam, durante muito tempo, quase que exclusivamente, por meio da LS com os pais surdos. Com isso, eles internalizam a estrutura sintática dessa língua muito mais do que a da língua oral. Isso poderá gerar certa confusão na hora de escrever, pois precisam utilizar a estrutura da LP que difere completamente da LS. Contudo, esses aspectos, normalmente, são totalmente negligenciados pela maioria das escolas brasileiras, uma vez que a maioria desconhece as implicações que a LS pode trazer ao desenvolvimento escolar desses alunos.

Diante desses resultados, queremos frisar a importância e urgência de se pensar políticas públicas de educação que (re)pensem a inclusão escolar dos filhos ouvintes de pais surdos.

Constantemente, nos indignamos ao falar dos traumas e sofrimentos causados aos surdos, por mais de um século, ao se tentar empregar a metodologia oralista - que deslumbrava o desenvolvimento da fala do surdo, desconsiderando que o ensino e aprendizagem, desse aluno, só poderiam ocorrer por meio de sua própria língua, a LS. No entanto, não percebemos que estamos recaindo na mesma falha. Só que, dessa vez, com a educação dos filhos dos surdos. Não podemos deixar passar um século inteiro para nos darmos conta de que as singularidades linguísticas e culturais dessas crianças, filhas de pais surdos, precisam ser consideradas no ambiente escolar, uma vez que elas podem, de alguma forma, afetar o desenvolvimento biopsicossocial desses sujeitos.

Nesse sentido, mostra-se fundamental que a escolaridade desses sujeitos seja discutida na disciplina de Libras que faz parte das grades curriculares dos cursos de formação de professores de todas as Instituições de Ensino Superior, para que, ao se depararem com esses alunos, os futuros docentes consigam articular teorias e práticas no que se refere à escolarização desses alunos.

\section{REFERÊNCIAS}

ANDRADE, P. R. Identidade de filhos ouvintes quando os pais são surdos: uma abordagem sociológica sobre o processo de socialização Dissertação (Mestrado em Sociologia) - Universidade Federal de Goiás, 2011. 
REVISTA X, Curitiba, volume 14, n.4,p. 256-276, 2019

BISHOP, M.; HICKS, S. L. Hearing, mother father deaf: hearing people in deaf families. Wahington, D. C.: Gallaudet University Press, 2008. BULL, T. H. Deaf Family Issues: CODAS and Identity. Web. 20 Oct. 2013. Disponível em: <http://portal.codaukireland.co.uk>. Acesso em: 9 mar. 2018.

BRASIL. Lei $\mathrm{n}^{\circ} .10 .436$ de 24 de abril de 2002. Dispõe sobre a Língua Brasileira de Sinais - Libras - e dá outras providências. Diário Oficial da República Federativa do Brasil, Brasília.

BRASIL. Decreto $n^{\circ} 5.296$ de 2 de dezembro de 2004. Brasília, 2 de dezembro de 2004; $183^{\circ}$ da Independência e $116^{\circ}$ da República. Diário Oficial da República Federativa do Brasil, Brasília.

BRASIL. Decreto Federal no ${ }^{\circ}$ 5.626, de 22 de dezembro de 2005. Dispõe sobre a Língua Brasileira de Sinais - Libras, e o art. 18 da Lei No 10.098, de 19 de dezembro de 2000. Diário Oficial da República Federativa do Brasil, Brasília.

BRASIL. Relatório do grupo de trabalho, designado pelas portarias $n^{\circ} 1.060 / 2013$ e $n^{o}$ 91/2013, contendo subsídios para a política linguística de educação bilíngue - Língua Brasileira de Sinais e Língua Portuguesa. Brasília. MEC/SECADI, 2014.

BULL, T. H. Deaf Family Issues: CODAS and Identity. Web. 20 Oct. 2013. Disponível em: <http://portal.codaukireland.co.uk>. Acesso em: 9 mar. 2018.

FERNANDES, S. Comunicação em Língua Brasileira de Sinais-Libras. 2.ed. Universidade Federal do Paraná - UFPR. Curitiba, 2012.

GONÇALVES, L. Gestuar e Ouvir: Divergências e Convergências entre os CODA licenciados em Tradução e Interpretação em Língua Gestual Portuguesa e os nãoCODA licenciados em Língua Gestual Portuguesa. Exedra Revista Científica. ESEC, 2012. Disponível em: <http://www.exedrajournal.com>. Acesso em: 09 jun. 2018.

GURJÃO, M. M. Aquisição da linguagem oral e de sinais por uma criança ouvinte filha de pais surdos: conhecendo caminhos. Dissertação (Mestrado em Ciências da Linguagem). Universidade Católica de Pernambuco, 2013.

HALL, S. A identidade cultural na pós-modernidade. Rio de Janeiro: DP \& A, 2006.

HADJIKAKOU, K; HADJIDEMETRI, E.; KONIDARI, M.; NICOLAOU, N. The Experiences of Cypriot Hearing Adults With Deaf Parents in Family, School, and Society. Journal of Deaf Studies and Deaf Education 14:4 Fall 2009. Disponível em: $<$ http://jdsde.oxfordjournals.org >. Acesso em: 09 abr. 2018.

KANTO, L.; LAAKSO, M.L; HUTTUNEN, K. Differentiation in language and gesture use during early bilingual development of hearing children of deaf parentes. Language and Cognition, 18, p. 769-788, 2015. Disponível em: <http://journals.cambridge.org $>$. Acesso em: 5 mar. 2018.

LANE, H. A máscara da Benevolência: a comunidade surda amordaçada. Tradução: Cristina Reis. Coleção: Horizontes pedagógicos. Lisboa: Instituto Piaget - divisão editorial, 1992. 
MELO, A. V. S. de. Children of deaf adults: CODAS em Sergipe. Revista Interfaces Científicas - educação. Aracaju, v. 3, n. 3, p. 85-91, jun. 2015. Disponível em: $<$ https://periodicos.set.edu.br>. Acesso em 09 nov. 2016.

MOROE, N. The Experiences of Hearing Young-Adults Growing Up In Deaf-Parented Families in Gauteng. Dissertation. University of the Witwatersrand, Johannesburg, 2013.

PEREIRA, O. R. Nascidos no silêncio: as relações entre filhos ouvintes e pais surdos na educação. Dissertação (Mestrado em Educação) - Universidade Metodista de São Paulo-Faculdades de Humanidades e Direito. São Bernardo do Campo, 2013.

QUADROS, R. M. de.; MASUTTI, M. CODAs brasileiros: Libras e Português em zonas de contato. In: QUADROS, R. M.; PERLIN, G. (Org.). Estudos Surdos II. Petrópolis: Arara Azul, 2007, p. 238-266.

QUADROS, R M. de. Educação de surdos: a aquisição da linguagem. Porto Alegre: Artes Médicas, 1997.

QUADROS, R. M. de. Língua de herança: língua brasileira de sinais. Porto Alegre: Penso, 2017.

SILVA, M. M. Codas Tradutores e Intérpretes de Língua de Sinais Brasileira: percurso para o profissionalismo. Dissertação (Mestrado em Estudos da Tradução) Universidade Federal de Santa Catarina, Centro de Comunicação e Expressão, 2016.

SKLIAR, C.; QUADROS, R. M. de. Invertendo epistemologicamente o problema da inclusão: os ouvintes no mundo dos surdos. Estilos da Clínica, São Paulo, v. V, n. 9, p. 32-51, 2000.

SOUSA, A. N. de; QUADROS, R. M. de. Uma análise do fenômeno "alternância de línguas" na fala de bilíngues intermodais (Libras e Português). ReVEL, v. 10, n. 19, 2012. p. 327-346. Disponível em: <http://www.revel.inf.br>. Acesso em: 03 out. 2016.

SOUSA, J. R. S. C. Crescer bilíngue: As crianças ouvintes filhas de pais surdos. Exedra Revista Científica. ESEC. Português: Investigação e Ensino. Número temático dezembro, 2012. Disponível em: <http://www.exedrajournal.com>. Acesso em: 03 out. 2016.

SOUZA, J. C. F. Intérpretes Codas: Construção de identidades. Dissertação (Mestrado). Programa de Pós-Graduação em Estudos da Tradução da Universidade Federal de Santa Catarina, 2014.

STREIECHEN, E. M. LIBRAS: aprender está em suas mãos. 2.ed. Curitiba: CRV, 2017.

STREIECHEN, E. M. A aquisição da Libras por crianças ouvintes filhas de mãe surda em um contexto multilinguístico: um estudo de caso. Dissertação (Mestrado em educação) - Universidade Estadual do Centro-Oeste do Paraná, 2014. 130p.

STREIECHEN, E. M.; CRUZ, G. C.; KRAUSE-LEMKE, C. Ouvintes e surdos, em casa e na escola: algumas intersecções (possíveis?). In: OLIVEIRA, J. P.; 
REVISTA X, Curitiba, volume 14, n.4,p. 256-276, 2019

ANTOSZCZYSZEN, S.; SORIANO, K. R. Educação Especial: desenvolvimento infantil e processos educativos. Curitiba: CRV, 2015.

STREIECHEN, E. M. Um estudante bilíngue, uma mãe surda e a escola: percurso de encontros, desencontros e contradições. Tese (Doutorado). Programa de Pós-Graduação em Educação da Universidade Estadual de Ponta Grossa/Paraná, 2018.

WRIGLEY, O. The politics of Deafness. Washington: Gallaudet University Press, 1996. 